\title{
A SiGe BiCMOS double-balanced mixer with active balun for X-band Doppler radar
}

\author{
Michaelsen, Rasmus S.; Johansen, Tom K.; Tamborg, Kjeld M. ; Zhurbenko, Vitaliy
}

Published in:

Proceedings. 2015 SBMO/IEEE MTT-S International Microwave and Optoelectronics Conference (IMOC)

Link to article, DOI:

10.1109/IMOC.2015.7369090

Publication date:

2015

Document Version

Peer reviewed version

Link back to DTU Orbit

Citation (APA):

Michaelsen, R. S., Johansen, T. K., Tamborg, K. M., \& Zhurbenko, V. (2015). A SiGe BiCMOS double-balanced mixer with active balun for X-band Doppler radar. In Proceedings. 2015 SBMO/IEEE MTT-S International Microwave and Optoelectronics Conference (IMOC) IEEE. https://doi.org/10.1109/IMOC.2015.7369090

\section{General rights}

Copyright and moral rights for the publications made accessible in the public portal are retained by the authors and/or other copyright owners and it is a condition of accessing publications that users recognise and abide by the legal requirements associated with these rights.

- Users may download and print one copy of any publication from the public portal for the purpose of private study or research.

- You may not further distribute the material or use it for any profit-making activity or commercial gain

- You may freely distribute the URL identifying the publication in the public portal 


\title{
A SiGe BiCMOS Double-Balanced Mixer with Active Balun for X-Band Doppler Radar
}

\author{
Rasmus S. Michaelsen ${ }^{(1,2)}$, Tom K. Johansen ${ }^{(1)}$, Kjeld M. Tamborg ${ }^{(2)}$, and Vitaliy Zhurbenko ${ }^{(1)}$ \\ (1) Technical University of Denmark, Department of Electrical Engineering \\ 2800 Kgs. Lyngby, Denmark \\ Email: tkj@elektro.dtu.dk \\ (2) Weibel Scientific A/S, 3450 Allerød, Denmark
}

\begin{abstract}
In this paper, we present an X-band doublebalanced mixer in SiGe BiCMOS technology. The mixer core consists of a LO Matched quad diode ring using diode-connected Heterojunction Bipolar Transistors (HBTs). The mixer is integrated with a low-noise, high-linearity active balun on the RF port and a miniaturized Marchand balun on the LO port. Experimental results shows a conversion gain of $+4 \mathrm{~dB}$ at 10.5 GHz with an LO drive level of $15 \mathrm{dBm}$. The LO-IF and RF-IF isolation is better than $36 \mathrm{~dB}$ and $26 \mathrm{~dB}$, respectively, in the entire band of operation. The input referred $1 \mathrm{~dB}$ compression point is better than $-11 \mathrm{dBm}$. The IIP2 is $+13 \mathrm{dBm}$ at a supply voltage of $3 \mathrm{~V}$ and $+16.5 \mathrm{dBm}$ at a supply voltage of $6 \mathrm{~V}$. The measured noise figure is found to be $\sim 6.5 \mathrm{~dB}$ at $10.5 \mathrm{GHz}$.
\end{abstract}

Keywords-Active balun, Marchand balun; mixer; MMIC; diode connected HBTs;

\section{INTRODUCTION}

High precision Doppler radars can be used for a high number of applications ranging from vital signs detection, tracking of aircrafts, UAVs, satellites, and space-shuttles to velocity tracking radars for artillery. The requirements to the dynamic range in the Doppler radar receivers continue to evolve as new applications emerge. The trend towards multiple receivers for phased array Doppler radars means that a monolithically integrated receiver with high dynamic range must be developed.

One of the most critical components in the Doppler radar receiver is the mixer. As the Doppler shift falls in the range from a few $\mathrm{Hz}$ to approximately $1 \mathrm{KHz}$, direct conversion mixers must be employed. It is well-known that direct conversion mixers suffers from DC offset problems and high 1/f-noise [1]. This has led to research into passive doublebalanced mixers using either CMOS resistive mixers [2] or diode-ring mixers [3]. In a SiGe BiCMOS technology, the 1/fnoise properties are believed to be best for the bipolar transistors compared to the MOSFETs. This is because the MOSFET suffers from traps in the oxide, which leads to an increase in $1 / \mathrm{f}$-noise. The bipolar transistors on the other hand are bulk conduction devices and have an order of magnitude lower $1 / \mathrm{f}$-noise compared to the surface channel conduction of CMOS devices [4]. Recently, the authors compared the $1 / \mathrm{f}$ noise performance of passive double-balanced mixers using diode-connected HBTs and Schottky diodes implemented in a $\mathrm{SiGe}$ BiCMOS technology. It was found that the diodeconnected HBTs lead to much lower 1/f-noise corner frequency than the Schottky diodes. Therefore, the diode-connected HBT in a ring structure is believed to be the most suitable mixer configuration for Doppler radar receivers. The use of passive baluns on the ports of the mixer, however, introduces significant losses which also increase the noise figure. Modifying the double-balanced mixer to include an active balun on the RF port should lead to radar receivers with lower noise figure. It is well known, however, that active baluns may lead to poor linearity. Therefore, techniques to improve the linearity of the active baluns should be employed in their design.

In this paper, the design of an X-band double balanced mixer with active balun on its RF port and passive balun on the LO port is reported. The mixer is fabricated in a $0.25 \mu \mathrm{m}$ $\mathrm{SiGe} \mathrm{C}$ BiCMOS process from Innovations for High Performance Microelectronics (IHP) in Germany. The technology features high-performance npn-transistors with a $f_{T}$ of $110 \mathrm{GHz}$ and $f_{\max }$ of $180 \mathrm{GHz}$. The technology has metalinsulator-metal (MIM) capacitors and five metal layers for passives and low-loss interconnects [5].

\section{CIRCUIT DESIGN}

The block-diagram of the double-balanced mixer is shown in Fig. 1. The mixer has the active balun placed at the RF port. A passive miniaturized Marchand balun is preferred at the LO port due to considerations about potential $1 /$ f-noise upconversion and bandwidth at the LO port. The IF extraction network of the mixer, shown in Fig. 1, provides the necessary return current path from the diode ring mixer core and shields the RF from the IF port.

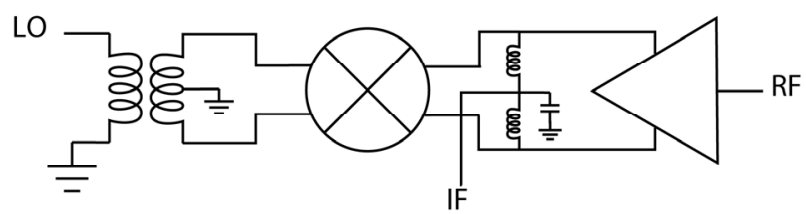

Fig. 1. Block diagram of double-balanced mixer.

\section{A. Active Balun}

Fig. 2 shows the schematic of the active balun. The design uses a differential cascode amplifier for high gain and good isolation. The input of one port of the differential cascode amplifier is matched using a shunt capacitor, $C_{i n}$, and series inductor, $L_{i n}$. The series capacitor, $C_{\mathrm{De}}$, is included at the input port mainly for coupling of the AC signal. The same type of 


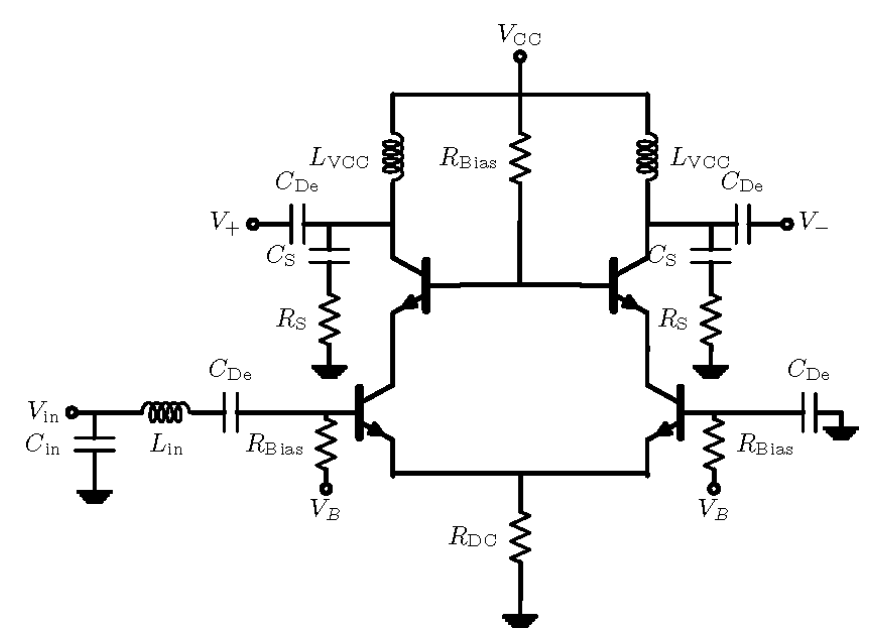

Fig. 2. Schematic of active balun.

capacitor shorts the AC signal at the unused input port to ground. This scheme allows easy biasing of the transistors through high valued resistors, $R_{\text {Bias }}$. The inherent high common-mode rejection ratio of the differential cascode amplifier converts the single-ended signal at the input into a differential signal at the output. The output is matched using an $\mathrm{RF}$ inductor, $\mathrm{L}_{\mathrm{VCC}}$, and series coupling capacitor, $C_{D e}$. The RF inductor also serves for biasing while the series capacitor is needed for decoupling the output of the active balun from the return current flowing from the mixer core. For increased stability, a series network consisting of $R_{s}$ and $C_{s}$ is placed at the output. The noise and linearity of the active balun is optimized by adjusting the sizes of the HBTs and increasing the bias current and voltage supply. The bias current of the differential cascode amplifier is set through the resistor $R_{D C}$. This choice is better than an active current source for highfrequency integrated circuits because of the lower parasitic capacitance [6]. The value of this resistor is chosen as a tradeoff between noise, common-mode rejection ratio, and required bias supply of the active balun. The nominal supply voltage, $\mathrm{V}_{\mathrm{cc}}$, is set to $6 \mathrm{~V}$. The layout is EM simulated and coupled together with S-parameter and Harmonic-balance simulations to give a realistic impression of the circuit before manufacturing. According to these simulations the active balun has a gain of $16.3 \mathrm{~dB}$ and noise figure of $4.8 \mathrm{~dB}$ at the center frequency of $10.5 \mathrm{GHz}$. The simulated amplitude and phase mismatch is below $1.5 \mathrm{~dB}$ and 3 degrees, respectively, over the band from 10 to $11 \mathrm{GHz}$. The input referred $1 \mathrm{~dB}$ compression point is $-6 \mathrm{dBm}$.

\section{B. Mixer Core}

The mixer core consists of a quad ring of diode-connected HBTs as shown in Fig. 3. The base-emitter junction is the preferred diode junction for mixer applications due to the heavier doping of the n-region of the emitter compared to the collector. The use of diode-connected HBTs with base and collector tied together also prevents substrate injection [7, pp. 477]. The heavy doping is necessary to reduce the so-called conversion-loss degradation factor [8]:

$$
\delta=1+\frac{R_{s}}{Z_{s}}+\frac{Z_{s} f_{R F}^{2}}{R_{s} f_{c}^{2}}
$$

where $R_{s}$ is the series resistance, $Z_{s}$ is the real diode junction input resistance (depends on pump power), and $f_{c}=1 /\left(2 \pi R_{s} C_{j}\right)$ is the cut-off frequency of the diode. From the high doping in the emitter, the diode capacitance, $C_{j}$, is expected to be high but simulations shows that the ratio of the design frequency to cutoff frequency $f_{\mathrm{re}} / f_{\mathrm{c}}$ remains low even at X-band frequencies. This observation applies at least for the small-area SiGe HBT's considered here and indicates that the mixer core operates mainly in a resistive mode. Inductors, $L_{\text {match }}$, are added to the diode ring structure to provide matching to the miniaturized Marchand balun at the LO port.

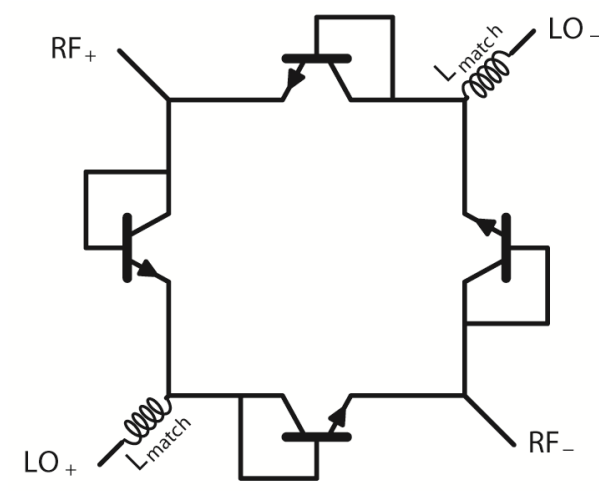

Fig. 3. Quad ring mixer using diode connected HBTs.

\section{Marchand Balun}

As mentioned above, a miniaturized Marchand balun is used at the LO port of the double-balanced mixer. The lumped-element representation of the Marchand balun is shown in Fig. 4. In this representation the input port is called $\mathrm{P}_{1}$ and the two complementary output ports are called $\mathrm{P}_{2}$ and $\mathrm{P}_{3}$. The lumped element representation uses offset broadside coupled spiral inductors, $L_{s}$, together with external capacitors, $C_{s}$ and $C_{m}$, to realize the quarter-wave coupled lines needed in the distributed Marchand balun. The inductive and capacitive coupling between the spirals is represented by $k$ and $C_{c}$, respectively.

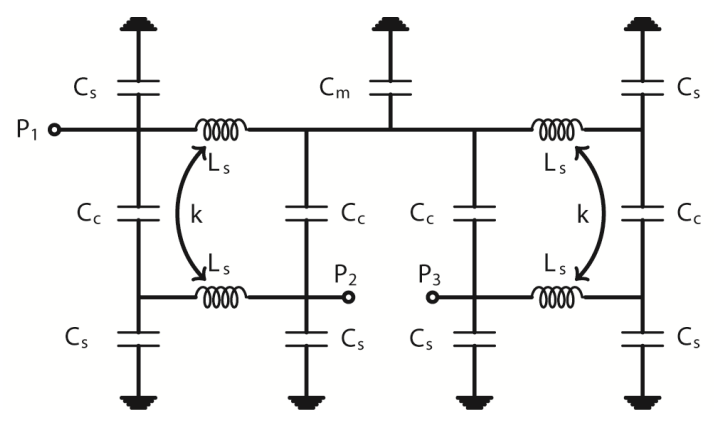

Fig. 4. Schematic of lumped element Marchand balun.

For equivalence with the distributed Marchand balun at the design frequency, $\omega_{\mathrm{LO}}$, the following design formulas are applied [9]: 


$$
\begin{aligned}
& L_{s}=\frac{Z_{o e}+Z_{o o}}{2 \omega_{L O}} \\
& k=\frac{Z_{o e}-Z_{o o}}{2 \omega_{L O} L_{s}} \\
& C_{s}=\frac{1}{\omega_{L O} Z_{o e}} \\
& C_{c}=\frac{1}{2 \omega_{L O} Z_{o o}}-0.5 C_{s} \\
& C_{m}=2 \times \frac{C_{c}-k C_{c}}{k}
\end{aligned}
$$

where $Z_{o e}$ and $Z_{o o}$ are the even and odd mode characteristic impedances of the coupled lines in the distributed Marchand balun. In practice it proofs difficult to simultaneously fulfil equations (1a) to (1e). For a given inductive and capacitive coupling of $k$ and $C_{c}$, respectively, detailed analysis shows that equation (1e) gives the sufficient condition for ideal balance in the Marchand balun. The most critical part for proper balun performance is thus to select $C_{m}$ to fulfil equation (1e). The minituarized Marchand balun is optimized using EM simulation. The simulated insertion loss at $10.5 \mathrm{GHz}$ is around $5.1 \mathrm{~dB}$ while the amplitude and phase mismatch is $0.18 \mathrm{~dB}$ and 0.7 degree, respectively. Simulation of the inductance, L, and the quality-factor, Q, of the spiral inductors is shown in Fig. 5. The rather high loss is caused by the low quality-factor of the broadside coupled spiral inductors.

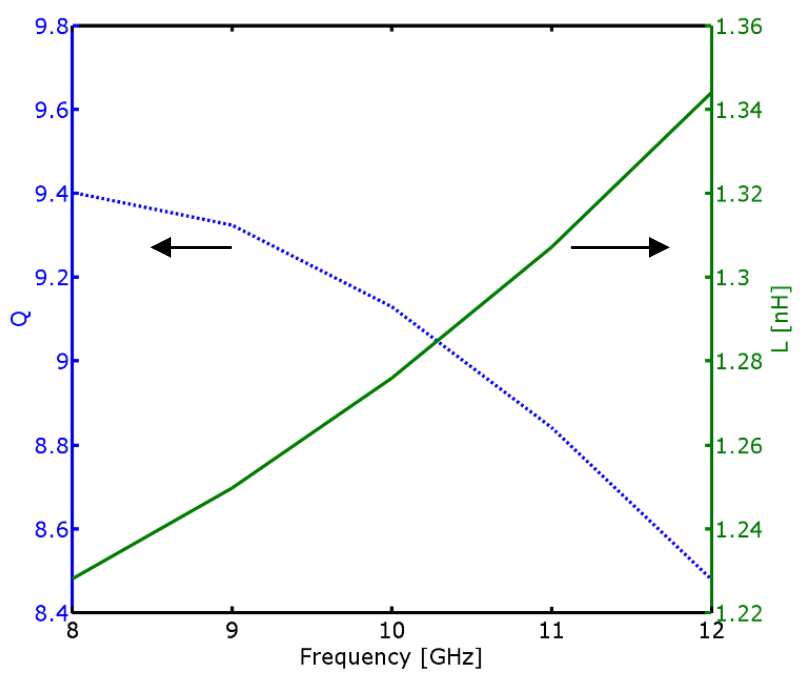

Fig. 5. Simulated inductance and quality-factor of spiral inductors.

\section{EXPERIMENTAL RESULTS}

In this section, the experimental results of the doublebalanced mixer are discussed. The measurements are made onwafer using a probe station. Losses in cables and probes are calibrated out. The microphotograph of the fabricated mixer is shown in Fig. 6 . The size is $1860 \times 1020 \mu \mathrm{m}^{2}$.

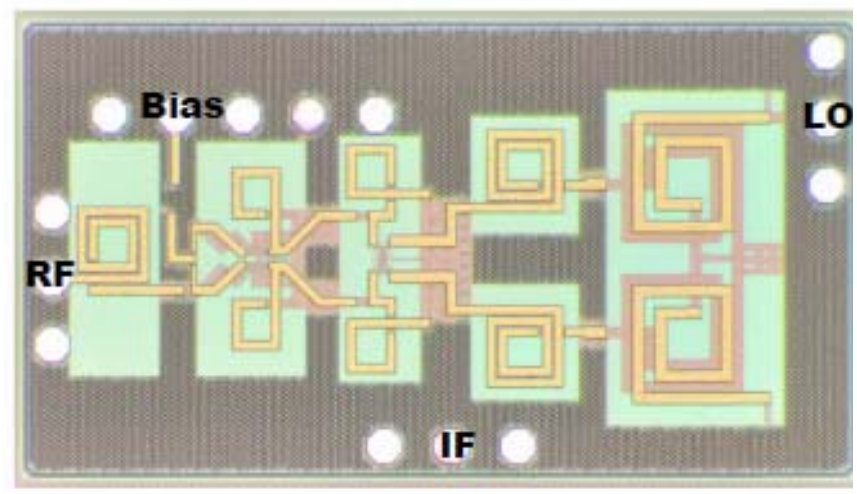

Fig. 6. Microphotograph of the double-balanced mixer, size is $1860 \times$ $1020 \mu \mathrm{m}^{2}$.

The conversion gain as a function of LO drive level for supply voltages of $3 \mathrm{~V}$ and $6 \mathrm{~V}$ are shown in Fig. 7(a) and Fig. 7(b), respectively. The measurements are performed on several samples with good uniformity. The LO frequency is set to 10.4 $\mathrm{GHz}$ and the RF frequency is set to $10.5 \mathrm{GHz}$. The current consumption for the two supply voltages are $17 \mathrm{~mA}$ and 38 $\mathrm{mA}$, respectively.

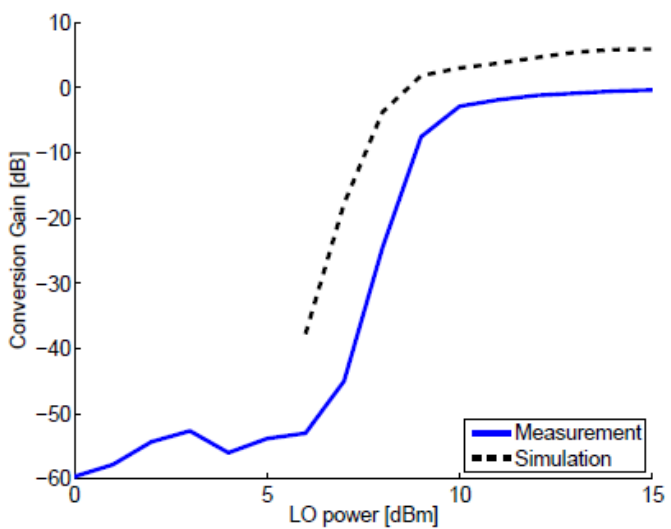

a)

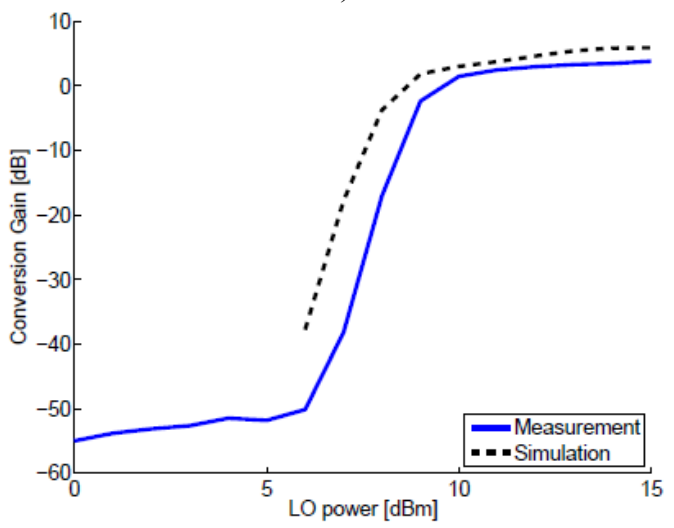

b)

Fig. 7. Conversion gain version $\mathrm{LO}$ power at (a) $\mathrm{V}_{\mathrm{cc}}=6.0 \mathrm{~V}$

The conversion gain at a supply voltage of $\mathrm{V}_{c c}=6.0 \mathrm{~V}$, shown in Fig. 7(a), saturates at a level around $\sim-1 \mathrm{~dB}$ for an $\mathrm{LO}$ drive level above $\sim 10 \mathrm{dBm}$. This is significant lower than 
predicted by the simulation. Reducing the bias voltage to $\mathrm{V}_{\mathrm{cc}}=3.0 \mathrm{~V}$, increases the conversion gain, as shown in Fig. 7 (b). The saturated level is around $4.6 \mathrm{~dB}$, well in line with the simulation. The exact reason for the observed behavior is as yet unknown. A possible cause may be that the collectoremitter voltages across the HBTs in the active balun with a supply voltage of $\mathrm{V}_{\mathrm{cc}}=6.0 \mathrm{~V}$ are so high (close to breakdown) that the transistor model becomes inaccurate. Fortunately, the performance of the double balanced mixer is acceptable at a supply voltage of $\mathrm{V}_{\mathrm{cc}}=3.0 \mathrm{~V}$. Therefore, all the following measurements have been performed at this supply voltage.

Fig. 8 shows the conversion gain as a function of frequency at a fixed IF of $100 \mathrm{MHz}$. The LO drive level is fixed at +15 $\mathrm{dBm}$. The conversion gain peak of $\sim 4.6 \mathrm{~dB}$ is around the design frequency of $10.5 \mathrm{GHz}$ and the $-3 \mathrm{~dB}$ bandwidth is $\sim 2.5$ $\mathrm{GHz}$. The bandwidth is mainly limited by the active balun. In general, the frequency response of the conversion gain is well predicted by the simulation.

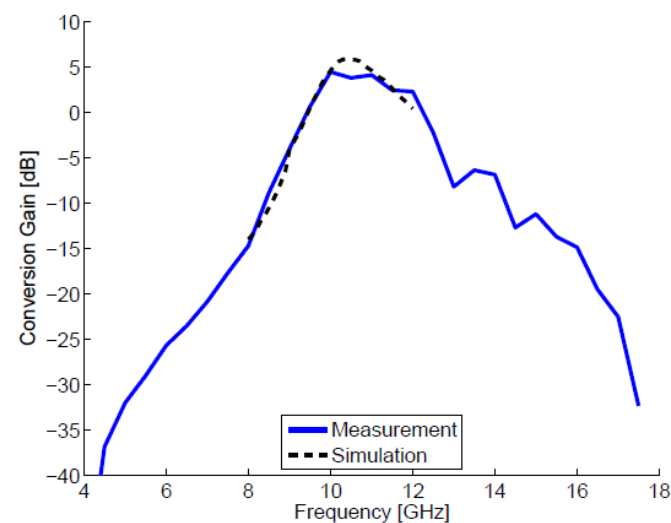

Fig. 8. Conversion gain versus RF frequency.

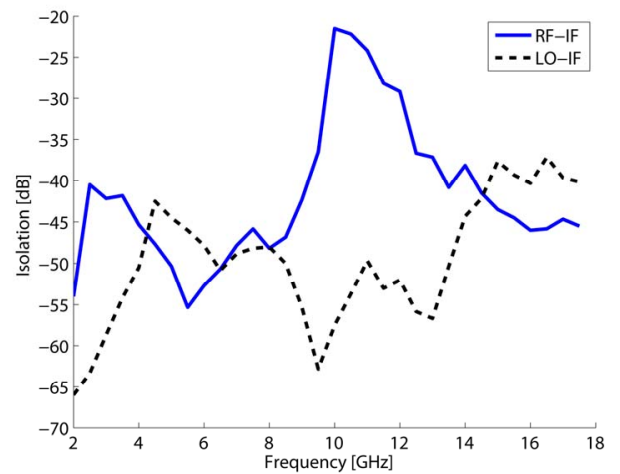

Fig. 9. LO-IF and RF-IF isolation versus RF frequency.

The LO-IF and RF-IF isolation version RF frequency is shown in Fig. 9. In the entire band of operation the LO-IF and RF-IF isolation is better than $36 \mathrm{~dB}$ and $26 \mathrm{~dB}$, respectively. These values indicate a good balance of both the active balun and miniaturized Marchand balun.

The measured $1 \mathrm{~dB}$ input referred compression point of the double balanced mixer is $\sim 11 \mathrm{dBm}$. This is somewhat lower than the $-6 \mathrm{dBm}$ simulated for the active balun alone but still acceptable for a mixer with active balun on its RF port. The input referred second-order intercept point ( $\left.\mathrm{IIP}_{2}\right)$ is measured with two RF tones at frequencies of 10.5 and $10.513 \mathrm{GHz}$ given a second-order product at $13 \mathrm{MHz}$. Isolators are placed after the signal generators to avoid leakage and intermodulation of the signals before they are applied to the mixer. Fig. 10 provides a comparison between the $\mathrm{IIP}_{2}$ both at a supply voltage of $3 \mathrm{~V}$ and $6 \mathrm{~V}$. The $\mathrm{IIP}_{2}$ measured at a supply voltage of $3 \mathrm{~V}$ is $+13 \mathrm{dBm}$ while it is $+16.5 \mathrm{dBm}$ at a supply voltage of 6 $\mathrm{V}$.

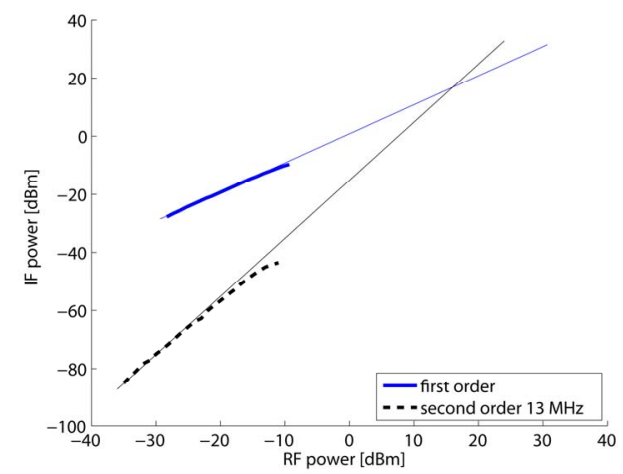

Fig. 10. Comparison of IIP2.

The single sideband noise figure versus RF frequency, shown in Fig. 11, is measured under the same conditions as the conversion gain in Fig. 8. It reaches a minimum of $\sim 6.5 \mathrm{~dB}$ around the design frequency of $10.5 \mathrm{GHz}$. Compared to the purely passive X-band double balanced ring mixer in [3] this represents an improvement of $\sim 3.3 \mathrm{~dB}$ due to the good noise performance of the active balun.

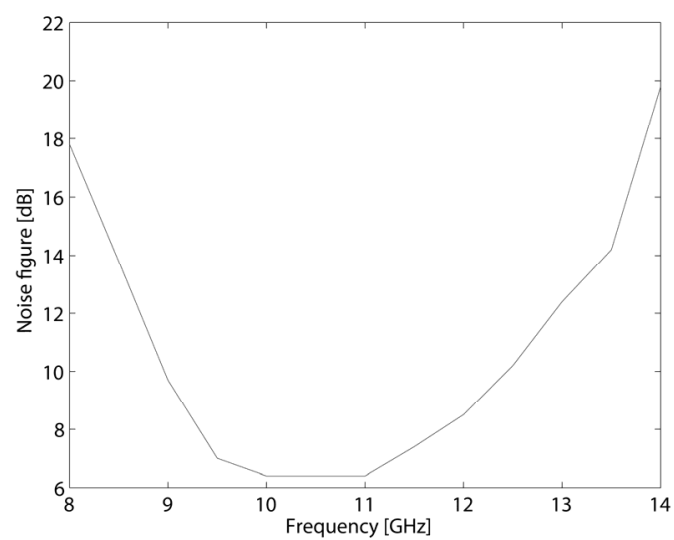

Fig. 11. Single-sideband noise figure versus RF frequency.

\section{CONCLUSIONS}

The design of a double balanced mixer in a $0.25 \mu \mathrm{m} \mathrm{SiGe}$ BiCMOS technology has been presented. The mixer is a direct conversion mixer for use in X-band Doppler radars. The double balanced mixer integrates an active balun optimized for low noise and high linearity on the RF port and a miniaturized Marchand balun on the LO port. The mixing elements consist of diode connected HBTs. 
At the design frequency of $10.5 \mathrm{GHz}$ the mixer has a conversion gain of $\sim 4.6 \mathrm{~dB}$ and a single-sideband noise figure of $\sim 6.5 \mathrm{~dB}$. It requires a relatively high LO level of $\sim 15 \mathrm{dBm}$ for best performance.

\section{REFERENCES}

[1] B. Razavi, "Design Considerations for Direct-Conversion Receivers," IEEE Trans. Circuits Syst. II, vol. 44, no. 6, pp. 428-435, June 1997.

[2] C. Song, O. B.-Lubecke, and I. Lo, "0.18- $\mu \mathrm{m}$ CMOS Wideband Passive Mixer,” Microw. Optical Tech. Letters., vol. 55, no. 1, pp. 23-27, Jan. 2013.

[3] R. S. Michaelsen, T. K. Johansen, K. M. Tamborg, and Vitaliy Zhurbenko, "Design of a broadband passive X-band double-balanced mixer in SiGe HBT technology," Int. Jour. Microw. Wireless Techn., pp. 235-242, 2014.

[4] J. Babcock, B. Loftin, P. Madhani, X. Chen, A. Pinto, and D. Schroder, "Comparative low frequency noise analysis of bipolar and MOS transistors using an advanced complementary BiCMOS technology," in IEEE Conf. Custom Integrated Circuits, pp. 385-388, 2001.

[5] IHP website: http://www.ihp-microelectronics.com.

[6] S. Voinigescu, High-Frequency Integrated Circuits, Cambridge University Press, 2013.

[7] M. Reisch, High-Frequency Bipolar Transistors, Springer, Berlin, Germany, 2003.

[8] S. A. Mass, Microwave Mixers, $2^{\text {nd }}$ edition, Artech House, Norwood, MA, USA, 1993.

[9] T. Johansen and V. Krozer, "Analysis and Design of Lumped Element Marchand Baluns," in IEEE MIKON conference proceeding, pp. 672$675,2008$. 